\title{
11th EUROPEAN REAL ESTATE SOCIETY CONFERENCE
}

\author{
2 - 5 June 2004
}

Milan

Expert judgement in the processes of commercial property market forecasting

Paul Gallimore (paul.gallimore@ntu.ac.uk)

School of Property \& Construction,

Nottingham Trent University, Nottingham, NG1 4BU, UK.

Patrick McAllister (p.m.mcallister@reading.ac.uk)

Department of Real Estate \& Planning, University of Reading, Reading, RG6 6AW, UK. 


\section{Expert judgement in the processes of commercial property market forecasting}

\section{Introduction}

Real estate market forecasts are now integral to decision-making processes for many major real estate investors, supporting asset allocation, real estate fund strategy and stock selection. With better availability of data and technology, modelling has become increasingly sophisticated, with a range of procedures now commonly used in real estate forecasting. These may include a combination of 'pure' judgemental techniques, theory-driven econometric methods and non-theoretical time series analysis. However, the quality of real estate forecasts reflects not just the quality of the forecasting model but also the quality of the organization's intervention in the formation and output of the model. In this paper, we examine the ways in which human (subjective) judgement impacts on the process of real estate market forecast production and the consequent effects on outcomes. In so doing, the research draws upon concepts both from cognitive psychology and from principal-agent theory that emphasise the potential of biases and incentives to influence the nature of task performance.

The academic literature on real estate market formation is now voluminous. We cite only a few examples below, drawing from Newell et al (2003). The last 15 years have seen rapid progress in the methodology of forecasting real estate rents, stock levels, returns, yields and cash flows (e.g: Benjamin et al, 1993; Brooks and Tsolacos, 2001; Chaplin, 1998, 1999, 2000; D’Arcy et al, 1999; Gardiner and Henneberry, 1988, 1991; Malizia, 1991; McClure, 1991; McGough and Tsolacos, 1995; Sivitanides, 1998; Wheaton and Torto, 1988). A great deal of research has been carried out on econometric and structural modelling of real estate markets (eg: Chaplin, 1999; D’Arcy et al, 1999; Gardiner and Henneberry, 1988, 1991; Malizia, 1991; McClure, 1991; McGough and Tsolacos, 1995; Tsolacos, 1998; Tsolacos et al, 1998). In addition there has been limited work on comparison of forecasting procedures (e.g.: Brooks and Tsolacos, 2001; Chaplin, 1998, 2000; Wilson and Okunev, 2001; Wilson et al, 2000). Confirming many studies outside the real estate sector, in many instances simple forecasts (e.g.: via naïve predictors) have been found to be more accurate than complex econometric models (Chaplin, 1999, 2000; Wilson et al, 2000). It is evident from academic literature that the majority of forecasting methodologies are based upon econometric modelling. 
The remainder of this paper is organised as follows. In the immediately following section, we examine the nature of, rationale for and effects of the use of judgement in forecasting. This draws mainly upon previous research in the forecasting literature but also includes a review of related research in real estate. The subsequent three sections outline the methodology and results of an interview study of UK real estate forecasters which focuses on the role and consequences of the use of judgement in the forecasting process. Finally, we draw conclusions.

\section{Judgement in forecasting}

In broader forecasting research, the role of judgement in statistical procedures and pure judgemental forecasting itself have been well-established research areas for two decades. However, relatively recently, Welch et al $(1998,97)$ were able to claim that their research "for the first time (our italics) connects the psychological study of human judgement with the substantial forecasting literature on extrapolation of time series data". In forecasting, there has been increasing interest in systematic biases that are (arguably) inherent to the processing of complex problems by human beings (e.g. Fisher and Statman, 2002). Such biases are well-documented in the literature, being based around the "heuristic" behaviours first identified by Tversky and Kahneman (1974) and subsequently investigated across a range of contexts, of which behavioural finance has been among the more fruitful. In the forecasting context, most interesting of these biases is the potential to succumb to (or avoid) the errors that arise through use of the "representativeness" and "availability". This growing interest in the implications of cognitive psychology underscores the importance of better understanding the role of judgement in the forecasting process.

We can identify five broad areas in which judgement can be introduced to the forecasting process. These are:-

i. Quantitative model formation.

ii. Evaluation and modification of quantitative model output by forecasters

iii. Evaluation of and modification of 'preliminary' forecasts by experts and users.

iv. The use of non-quantitative (pure judgemental) forecasts.

v. Implementation of forecasts by users. 
In this paper the main focus is on econometric models and the ways in which their outputs are produced and mediated. Although they are widely used in the wider business community, we do not discuss the use of "pure"judgemental forecasts.

For econometric models, it is generally accepted that a purely objective forecast is unattainable. The 'right hand side' variables are selected on the basis of a combination of theory and empirical research. Judgment is unavoidable in the selection of variables to be included - the omitted variable problem is a common cause of model misspecification. In terms of the specification, "mathematical models involve smoothing constants, coefficients and other parameters that must be decided by the forecaster" (Walonick, 2004, 2). These choices will influence the forecast output. The forecaster will also have to make decisions about forecast horizon, forecast interval, data selection, data treatment and choice of computational model. Focusing on financial modelling, Thomaidis $(2003,14)$ points out that

\footnotetext{
"An integral part of econometric modelling is the selection of appropriate financial data and an initial filtering method to reduce unnecessary noise. At this stage both good domain knowledge and good statistical methods are important. The two initial stages are the most crucial steps in the modelling process"
}

The widely acknowledged limited availability and capriciousness of much real estate market data means that data issues often involve critical forecaster decisions. Further, notwithstanding the above, there are also limitations to pure mechanical forecasting processes that force judgmental intervention on forecasters.

An underlying assumption of econometric forecasting is that past patterns will continue into the future. Or, as Guilkey (1999) more vividly puts it: better econometric modelling only forecasts the past with greater precision. Although Clements and Hendry (1999) ascribe forecast failure to factors such as inadequate theory, inaccurate observations and structural breaks, they argue that it is structural breaks that are the underlying cause of forecast failure. They emphasise the role of political, economic and technological shocks in causing shifts in the economic data that render previous models obsolete. This produces a situation where model specification can be irrelevant to performance, in that correctly specified models can be outperformed by poorly specified models. However, another source of forecast failure is inaccuracy of forecasts of the 'right hand side' variables. 
Where many of the explanatory variables are also forecasted, Fildes and Stekler (2002) emphasise the importance of treatment of forecasts of model inputs. For instance, previous 'outsourced' forecasts of explanatory variables may in the past have displayed systematic errors e.g. were too pessimistic or optimistic. Turner (1990) illustrates that variations in the way in which forecasters decide to incorporate such knowledge (sometimes called 'putting the model back on track') will produce variations in forecasts. Given the wide range of potential sources of error in 'pure' model output it is not surprising that the use of judgement subsequent to model application is often regarded as a positive contribution to the forecasting process.

The value of the contribution of judgement to forecast output, relative to model output, will be a partial function of the credibility of the forecast to both forecasters and users. This will be affected by the modelling issues already discussed such as quality and availability of data, explanatory power of model, uncertainty (confidence intervals) in the forecasts and stability in the forecast environment. Where there have been recent shifts in relationships between variables or events create new conditions, statistical output may need to be subjectively adjusted. Research has shown that there is indeed widespread use of expert opinion in the formation of forecasts (Dalrymple, 1987). However, this can be a double-edged sword since market experts bring, often crucial, contextual knowledge while being subject to the biases and inconsistencies noted above (Batchelor and Dua, 1991).

In addition, researchers are increasingly acknowledging that forecasters (far from uniquely) are social entities, with individual characteristics that interact with institutional, social, political and cultural contexts, in turn, influencing forecast outcomes (Gjaltema, 2001). An obvious example is the much cited bias of equity analysts in optimistic forecasting of the performance of companies who are clients. The equity analyst scandals have highlighted that forecasts can often be disseminated throughout an organisation or made public, can be controversial and contested and then can be tested and falsified. There can, therefore, be a whole range of incentives and pressures on forecasters.

It is not surprising then that from an agency perspective, Corder (2003) suggests that there are often incentives for a rational bias in forecast outputs. For instance, Laster et al (1999) concluded that forecasters consider both forecast accuracy and potential 
publicity in selecting forecast outcomes. They found that forecasts which are made to generate publicity tend to be further from the consensus than forecasts generated by analysts in other sectors. The balance between the need for publicity and a requirement for accuracy provides conflicting pressures for convergence (herding) and divergence in forecasts. Croushore (1997) suggests that

"some (survey) respondents might shade their forecasts more toward the consensus (to avoid unfavourable publicity when wrong), whilst others might make unusually bold forecasts to stand out from the crowd."

By emphasising the importance of users' "prior commitment", Armstrong (1985) implicitly recognises the need for acceptance of forecasts by users. He also suggests that forecasts with unpleasant consequences can often create problems with the response being to change the forecast rather than the plan. For instance, Griffith and Wellman (1979) found that hospitals purchased forecasts and then ignored those with pessimistic outcomes. This may reflect a bias of avoiding disconfirming evidence and seeking confirming evidence. Interestingly, when examining how the trend in time series influences judgemental extrapolation, O'Connor et al (1997) found that people have significant difficulties dealing with downward sloping series.

Linked to the incentives for forecasters to herd and to maintain credibility, a corollary is that there is a lack of volatility in forecasts relative to actual outcomes. Clements $(1995,419)$ investigated the role of judgement in creating excessive smoothness in forecasts and tentatively conclude that judgemental "adjustments tend to reduce the variation over time in forecasts". In seminal work in this area, Nordhaus (1987) speculates that the lack of volatility in forecasts relative to actual outcomes could be due to factors such as the need to reach a consensus and to maintain forecast credibility by avoiding major 'jumps'.

As noted above, the majority of work on real estate market forecasting has focussed on statistical techniques and there has been limited work on the use of judgement in forecasting. However, despite this increased sophistication in forecasting methodologies, it has been recognised that differences in real estate forecasts still occur due to differences in the structure of the econometric models, statistical procedures and data used (Mitchell and McNamara, 1997), as well as the use of potentially flawed economic forecasts (Higgins, 2001). In the US, Guilkey carried out 
a detailed analysis of private sector real estate forecasting models in terms of their parameters, methodology and outputs. He identifies important differences in their variables used, model specifications, the exogenous variables which are obtained from macro-economic forecasts providers. With regard to the latter, he found that the organisations providing macro-economic forecasts to real estate forecasters used different explanatory variables. Where they had overlapping explanatory variables, the three macro-economic forecasting providers were using different assumptions about interest rates, federal expenditures, exchange rates, GDP growth. He also finds that after the forecasts are determined econometrically, "all three of the major players reserve the right to subjectively alter the forecasts on the basis of specific information they have about the MSA" (Guilkey, 1999, 30). In turn, even where real estate forecasters are using the same provider of macro-economic forecasts, the data is being 'massaged' very differently by the different providers. As a result, he identifies widespread disagreement amongst forecasters concluding that

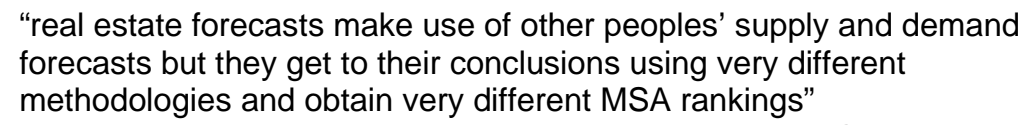

(Guilkey, 1999, 40).

In research that measured the accuracy of real estate market forecasts in the UK, Newell et al (2003) found evidence of forecast inertia. They concluded that persistent over-estimation and under-estimation in real estate forecasts suggested a smoothing or inertia effect in which significant new information is needed before major revisions to prior real estate forecasts are done.

The foregoing gives reason to believe that subjective human judgement, exercised by experts and applied to quantitative forecasting model outputs, is both an important and complex dimension in the process in forecasting real estate markets. The following sections describe an investigation of this process as it operates in UKbased forecasting providers.

\section{Methodology}

Given that the subject under investigation was expected to involve at least some complex behaviours and relationships, it was considered that it was unlikely to be as effectively modelled by an approach based on traditional positivist assumptions as by an interpretivist approach (broadly termed). The latter was therefore chosen as a more appropriate basis for the research design, and adopted in a pragmatic fashion, 
seeking an appropriate balance between the need for generalizability and participant authenticity.

The technique chosen for data collection was semi-structured interviews. Nineteen interviews, each approximately one hour long, were conducted with individuals who were either responsible for the production of property market forecasts and/or for the production of property market forecast advice that incorporated the use of such forecasts ${ }^{1}$. The individuals within this sample frame represent, in the view of the researchers, a very substantial sub-set of the property forecasting services available from UK-based organizations. The resulting quality of this sample lends support to the authenticity of the findings as representative of the UK property market forecasting "industry". It should be borne in mind, however, as expanded upon below, that this industry is itself relatively small in relation to the number of providers and, within this provision, diverse as to its intrinsic functions and its integration with other property services.

The interviews were guided by a common question framework that had been developed from the researchers' prior knowledge of the subject and from a review of the literature (supra). The purpose of this framework was to ensure that, as far as possible, the data collection focused on the specific area of research interest, both across the sample and in relation to each respondent. It is acknowledged that by controlling the interview agenda ${ }^{2}$ this approach involves a potential compromise between generalizability and discovery. This is not, however, regarded as a significant problem in the study and is in any event mitigated by the interviewees having been invited, at the end of the interview, to discuss any other issues not prompted by the interviewers' questions.

Both researchers were present at all of the interviews. In order to facilitate reflection upon and analysis of the interview data, all interviews were, with the agreement of the interviewees, recorded and subsequently transcribed. The analysis and interpretation was further assisted by the use of textual analysis software. ${ }^{3}$ This enabled selected passages of the transcribed interviews to be coded against

\footnotetext{
1 At four of the interviews an additional person was present. This was in each case someone with experience of property market forecasting, working with the interviewee.

2 i.e. By excluding an invitation to talk about things which interviewees may have wished to talk about, but which were not prompted by the framework.

${ }^{3}$ QSR NVivo version 2.0.163.
} 
particular concepts or themes. While this coding is possible manually, the software improves subsequent organization, retrieval, inspection and manipulation of the material covering these concepts and themes, including exploration of linkages, and efficient viewing of the context from which the passages are extracted. This aids the researcher in the task of developing a fuller understanding of the interview material.

In order for this coding to be carried out, it is necessary to identify the underlying concepts or themes. In the present study, these were identified by reference to the ideas that formed the initial interview framework, added to by the researchers' own reflections on what they recalled as salient issues emerging from the discussion. Further additions and refinements to the codes were made in the process of coding itself, as reading of the transcripts revealed new themes or modifications to existing ones. In strict methodological terms, the pre-coding of the data, even if only partial, imposes an element of the researchers' own structural understanding on the analysis. Providing the initial coding is treated as provisional, however, the approach adopted in this study is regarded as an acceptable strategy in the literature (Miles \& Huberman, 1994).

Each code was given a name (in some instances cryptic, because of the naming limitations in the software) and an accompanying description. The description is important because what matters is the meaning of the concept, within its context, rather than its name. This led to the identification of 61 codes, shown in alphabetical order in Appendix 1 alongside their descriptions. The transcripts were accordingly coded. In order to achieve consistency across all the transcripts (i.e. to ensure maximum reliability in the use of the codes) the coding of all transcripts was carried out by one of the researchers. A check was conducted by having the second researcher code three randomly selected transcripts. The outcome of the resulting comparison pointed to substantial agreement across most codes but with a small number of differences ${ }^{4}$. However, since interpretation of the transcripts against these codes would be carried out by both researchers, inter-actively between themselves, this level of difference was considered to be acceptable.

\footnotetext{
${ }^{4}$ Evaluation of the level of agreement was done intuitively rather than through the use of an inter-coder agreement measure, since the latter would require the adoption of a protocol for determining agreement/disagreement. Given that this would have a degree of subjectivity, and given the nature of the material, the researchers do not believe such a quantitative measure would add to the credentials of the analysis.
} 
During the analysis and interpretation, these codes were grouped and cross-linked (and, in a few cases, coalesced) so as to better clarify the nature of the underlying ideas and the relationships between them. This led to five major groupings. One grouping covered the context within which the forecasting was being carried out, and was to an extent factual in nature (e.g. what variables were being forecast, what markets etc). The other four groupings centred in turn upon: how forecasts were communicated to users and then used; issues surrounding the forms of econometric models that were being used; the ways in which forecasters evaluated their success or failure; and how quantitative forecasts might be adjusted by the qualitative judgements of "experts". What follows in this paper is principally directed at the first (the context) and last (the qualitative adjustment process) of these groupings. The other results will be reported elsewhere.

\section{The context of forecasts}

\subsection{The interview sample}

All nineteen main interviewees had current and prior involvement in the production of property market forecasts. The nature of this involvement varied across the sample ${ }^{5}$. While all had responsibility, mostly at a senior level, for some or all of the organization's forecasts, their role in production varied along a spectrum from detailed involvement in the mechanics of statistical modelling through to mere oversight of the process, the implementation of which was carried out by others. The term "forecaster", used in this paper to describe these people, must be interpreted taking this variability in function into account.

The organizational profile of the 19 interviewees was as follows. Six worked for organizations whose core business was property consultancy and agency ("agents" in the traditional "jargon") ${ }^{6}$; six worked to support the fund management activities of their employing organization; two worked for banks; and one was responsible for forecasts in a large publicly quoted property company. Of the remaining four, two worked in organizations where the primary function was forecasting (although only one of these was focused solely on property); and two were in organizations offering forecasting advice as part of a broader investment advisory service. Within these broad categories, the actual role of the interviewees in forecasting varied. One obvious variation was in the geographical spread of the forecasting focus. Although

\footnotetext{
5 In some cases the interviewee's experience had been gained in more than one organization.

${ }^{6}$ A further three, not in this category, also had substantial experience of working as forecasters for property consultants/agents.
} 
all those interviewed were involved to some degree in forecasting of UK markets though in some cases highly centred on key markets - several also had a strong European market focus. Another difference was in the extent to which those forecasting were involved in the process of investment decision-making. This was more likely to be the case within the fund manager category.

\title{
4.2 Variables forecast
}

In both the UK and Europe ${ }^{7}$, the property market variable most frequently forecast is change in rental value. In large part, this is because information to support modelling of these rents is more widely available than for other property-specific variables. This rent forecast is usually for prime, "avoiding extreme locations". This was referred to as a "top rent" but also as "prime/average" and in one cases "average rather than prime", indicating some variation in perceptions of this benchmark. Almost invariably, it is nominal rents that are being forecast, but one interviewee made the distinction between these and real rents:

\begin{abstract}
"Theoretically, any economist would say you ought to be modelling the rate of change in real rents but that does not necessarily mean that that is how real estate markets actually operate. Empirically, we find in most cases the rate of change of nominal rents works better than the rate of change of real rents".

(Forecaster working for Bank) $^{8}$
\end{abstract}

In some cases, these prime forecasts are augmented by forecasts for other grades of property, usually where the forecasting organization owns such property and wants to project returns for existing assets or funds. Where these additional forecasts are not produced, fund managers are expected to adjust the prime figures when applying them to different grades of property. An exception to the "prime" basis is the wellknown alternative basis of the (now) CB Richard Ellis index: "we're forecasting the best building in the best location with the best tenant".

The forecasting of yields is also undertaken, to a lesser extent than rents, and usually in conjunction with total return forecasting. For total return, the yield forecasts were frequently done by reference to the Investment Property Databank (IPD) indices, at the all-property and major sector and segment levels. Alternatively they were

\footnotetext{
7 In Europe, the markets and sectors for which the key variables are forecast is more limited than in the UK - see page 12.

8 The attributions relate to the organization in which the forecaster was working at the time of the experience being described (and not always the organization in which they are currently working). The attribution is styled "Forecaster working for..." throughout to remind readers that it is the forecaster's views and experience that are being examined and not that of the organization, per se.
} 
performed to feed into valuation models, applied to the organization's portfolio to generate total returns going forward. One interviewee made the distinction being UK and US practice in this regard:

"In the UK, we get total returns by forecasting value change, which is driven by rents and yields here, and income return, so you need to forecast the yield shift. In the US we don't disaggregate those components of change in value, we just value change."

(Forecaster working for Forecaster/Investment Adviser)

A number of interviewees, however, pointed to problems with yield forecasts, where their experience had been that they "were far too difficult" or had "been failing hopelessly".

Prime vacancy rates are also forecast by some, but by no means as extensively as rents. The same is true of depreciation forecasts, although this appeared to be done is a fairly rudimentary way, and generally expressed as long-term averages for different markets.

\subsection{Markets and sectors forecast}

The forecasting carried out by the interviewees varied widely in relation to the markets and geographical scope of coverage. For the UK, most are producing forecasts at national and regional level of the main market sectors - retail, office, industrial - with some doing (usually) selective sub-analyses of these either by type (e.g. retail warehouse, in-town retail) or location. Outside of London, the local forecasts go down to individual town-, or, in some cases, or county-level. The extent of the coverage and sub-sector analysis was naturally driven by the kind of service the forecasters were seeking to provide, which in turn was a function of the kind of organization in which they were working.

While providing a broad overall service, some focused on specific types in particular regions - the most obvious example being prime offices or retail in one or more of the central London sub-markets - because that is where the organization's or client's property focus lies. Conversely - for the same reason - some forecasters ignored some sectors or regions (with the example of Welsh industrials being cited more than once as holding little interest for clients). In a couple of cases, the view was put that regional forecasts were sometimes of little use, justified in one of these cases because of the scarcity of suitable properties in some regions.

"We don't often produce regional forecasts because the regions are of very little consequence and it becomes very location specific. We have 
to do London, Thames Valley, Scotland and the rest of the UK but we've abandoned doing regular forecasts of South West, East and East Anglia etc. It is really of very little consequence what you think of East Anglia when there are really only three of four centres or one regional head office location...so you have to get past the region."

(Forecaster working for Property Consultant)

This recognition of the importance of getting down to the local town or city level was repeated often, though practical considerations relating to the quality and long-run availability of data militated against its implementation. With large portfolios - one interviewee referred to clients with four or five hundred properties - another factor working against the production of local level forecasts was the scale of the task.

For Europe, and reflecting the relative immaturity of European property markets, the focus is on major cities or even centres within those cities. Most notable in the latter respect are the major office centres, although most interviewees who are involved in Europe described activity or plans to extend into retail (both "High Street" shopping centres and out-of-town) and into secondary office locations. All appeared to be in the process of extending the number of cities for which they prepared forecasts. A few were already well under way (e.g. one producing forecasts for 21 office markets, 11 retail markets and 11 industrial markets). This process, driven by investor demand for assets in these locations, appears constrained at present, however, by the shortage of an adequate supply of robust data upon which to base forecasts.

\subsection{Frequency of production and forecast horizon}

Most forecasts produced by those in the interview sample were done so on a quarterly basis. This appears to be driven by the fact that the economic data, which constitute the most important inputs to most models, are themselves updated quarterly. Sometimes, this linkage was less strong, and so the frequency was biannual or even annual. This occurred, for example, where, rather than adopt directly economic data from an outside source, the forecast would utilise a "house view" on the economic inputs, with this being adjusted less frequently than quarterly. Another justification for less frequent up-dating is because of the perceived pace of normal property market movements.

"We do bi-annual forecasts because in normal market conditions the property market isn't that fast moving, so that seems to work reasonably well"

(Forecaster working for Property Consultant)

Local models are another exception, where they are cross-sectional in form and so by their nature are less tied to runs of economic data. These tend, in at least some 
cases, to be either updated only every six months or produced an ad hoc, rolling basis.

The most typical time horizon for forecasting is five years. The reasons for this are based on the typical time horizon over which forecasts of the economic inputs are available, coupled with a widespread view that at or beyond five years (or thereabouts) there is a strong likelihood of a reversion to a long term trend. This trend reversion was often described in terms of the property market cycle, although views differed as to whether this meant it was difficult to know where the cycle would be at the forecast horizon or, by contrast, that one could assume that the term of cycle was typically five years:

"We will revert to that long term trend after the end of the forecast horizon and will make clients aware that we're not sure where we will be in the cycle at that stage."

"When you start your forecast you're at a certain point in the cycle and if you take your objective as trying to plot how the market will move through the remainder of this cycle, five years seems reasonable."

(Different Forecasters, both working for Property Consultants).

Three to five years was also justified as a suitable horizon for investors who are using the forecasts to plan trading or capital investment decisions. In some cases forecasters are producing longer term forecasts - typically ten, twenty or, in one extreme instance, 40 years - but generally solely for internal use, or at the specific request of clients (e.g., bank clients, because of the longer term nature of their loans). There was some scepticism, however, about the merit of going beyond five years: "after 10 years, it's a lifetime away".

In some instances the horizon is shorter, and one interviewee, working for a property consultant, suggested that a lot of clients sought forecasts with a two-year horizon. Others questioned the value of short-term forecasts, especially over the very shortterm, given the investment horizons of most property investors:

"Most real estate investors in our world, at least, aren't particularly interested in what is going to happen in the next six months since once you've bought something, you're going to hang onto it for several years." (Forecaster working for Bank).

\subsection{The purpose and use of forecasts}

There variety of reasons for producing forecasts matched the variety in the forecasts themselves. For those forecasters working within investing organisations, one of the 
primary purposes is to predict the future performance of existing or prospective asset groups, to assist in making decisions about what to buy or sell (including spotting current mis-pricing, by comparing the returns based on the predicted cash flows with the returns implicit in current market pricing) or what allocations to put into funds. Investing organisations may also use internal forecasts to support specific acquisitions; although this may be reinforced by external forecasts when, for example, the size of investment demands it.

Where the question in an organisation is the extent of the allocation to property, rather than whether to invest in property, the focus for the forecasting is to determine the relative performance of different sectors and/or assets.

"We get given the money, we have money in property, that's it, end of story. So what we need to do is make the most out of that money. What we are therefore concerned about is, are the forecasts getting the relativities right?"

(Forecaster working for Fund Manager)

Where property consultants are responsible for managing funds, they may use their own forecasts as inputs into strategic investment decisions for clients' portfolios.

Forecasts produced by property consultants may also be used to support specific cash flow analyses undertaken on behalf of clients, at varying levels of detail and transparency: They are also used to support more general client-specific requests for advice on specific markets. This work may often precede the more detailed cash flow forecasting later applied to specific assets in that market. In this sense forecasting is viewed not as an end in itself, but rather as part of larger package to provide the level of advice clients require to enable them to make informed decisions and enhance those decision processes.

"Once they have then gone into the market and they've got three different buildings to look at, then you will start doing some cash flows. What they want to know is, yes, Brussels is going to outperform Paris, now is a good time to go into the market, is it going to be driven by yield compression, what sort of building should they use. So it's not numbers, it's advice, forecasts are part of what leads to." (Forecaster working for Property Consultant)

"We do have direct income from forecasting but also it supports internal clients in fee-bearing work that they're doing, in holistic property advice of which a small part could be the property forecasting side or could be the property forecasting side going into the strategic side, with a separate investment strategist actually building on the work that I do." (Forecaster working for Property Consultant)

In one instance, this advice was being formulated in a "brokerage" fashion, being combined with market based data on transactions and deals to arrive at definitive 
buy-sell-hold recommendations. For forecasters such as this, whose service offer included broader investment advice, credibility was important and forecasting was an important means of securing this.

"If I go into meetings with clients and link the results of my forecasting analysis to deals, to my understanding of what actually drives the market, then I will be taken seriously and will be able to influence decisions. Which is the be-all and end-all of why you are forecasting."

(Forecaster working for Fund Manager)

Forecasts are sometimes regarded in some sections of the industry as produced largely for general profile-raising of producers with current or prospective clients or investors. With some exceptions, however, this did not figure prominently in the interviews.

\subsection{The form of models}

In the virtually all cases, the forecasting was based on some form of econometric modelling. For all but local markets, this was based on time-series analysis, almost invariably using multiple-regression. Local market forecasting (with the notable exception of the London markets) was more likely to be based on cross-sectional models, typically built from assembling local market information or local economic information about a particular town. In some instances, an alternative approach was adopted, with local models derived in a top-down fashion from regional or national level forecasts. This necessitated the local forecast being driven by the historic relationships between, for example, a local authority area and its region, or a town and its region. Achieving consistency in the nesting of different levels of forecasts was described as sometimes problematic (i.e. the sub-forecasts did not add up to the whole).

For time-series regression models, office markets were the most developed. For these markets, forecasters appeared to have the same overall specification for timeseries models across different markets, but work with different coefficients. The relationship between rents and vacancy rates was seen as central to understanding and prediction in office markets. Determining vacancy requires, in turn, separate models to forecast demand and supply variables.

"For office markets the basic equation is the rate of change of rents as a function of the level of vacancy. There is a natural rate of vacancy and if vacancy is above that then rents will fall, and the more above it is, the faster they will fall. Retail markets are much more difficult, because we haven't got vacancy for most retail markets."

(Forecaster working for Bank) 
"We take a multi-equation approach, using the relationship between net absorption or gross take-up, and historical demand drivers. We'd project that forward, with our assumptions based on local research projections of what's happening on the supply side. We'd then look at the relationship between vacancy and rents, which encapsulate the supply-demand conditions. This would feed into a vacancy rate projection.....and that drives rents."

(Forecaster working for Property Consultant)

This process has problems, because for not all markets are there time-series for supply and for demand variables, causing modellers to resort to proxies (e.g. take-up for demand). This was described as most acute on the supply side, where in some markets the supply data, "of various degrees of plausibility", only tends to go back for a short period, and in some markets doesn't exist. Again proxies were used (e.g., change in rents at some point in the past as a proxy for current vacancy levels).

Forecasting of rental growth generally utilises basic macroeconomic variables, such as measures of consumer expenditure, inflation and economic output, each of which in turn will have been forecast. Forecasters use these forecasts as inputs to their property models, but may adjust the input forecasts depending on their own view of the economy.

Macro-level variables were considered to have limited use in forecasting local markets, in that they appeared to show little historical correlation in general or at turning points in particular. The sophistication of these local models varied, depending upon the maturity of the markets. Where these local models were crosssectional, there appeared more susceptible to change, attributed to their greater reliance on qualitative information.

Retail forecast models presented different problems to office market models. Vacancy rates were generally not available so retail models were described as largely a function of retail demand (a reasonable assumption, for high street retail at least, where supply may well be fixed). Modelling industrial markets was seen as combining the difficulties of suitable demand and supply data.

\section{Making qualitative adjustments}

The interviews conducted for this study confirmed that, almost universally, the first, essential stage in the process of producing property market forecasts is one based on quantitative modelling of historic and/or (other) forecast data, typically using regression techniques. It is equally clear, however, that the process does not stop at 
the output from such models. Again, almost universally, some form of qualitative judgement or influence is brought to bear on the output, which frequently causes the forecasts either to be adjusted, or qualified, before they are passed on to users. What follows is a description of the nature of these judgements and influences, as revealed by the interviews.

\subsection{In-house judgements and influences}

The most immediate kind of feedback is that available within the producing organization from people who may not use the forecast themselves, but who share some form of common interest with those who will use the forecast (e.g. agents). The importance of this form of feedback obviously depends upon the type and range of advice within the organization. Where this advice is available from people actually working for the organization "on-the-ground" in the markets - something more likely in the property consultant/agent organizations - it can take two forms. First there is factual data that may be known to the people in the market, but is not typically or easily available to the forecaster. Second, there is a more qualitative kind of feedback, typically represented by market sentiment, or knowledge of the current preferences of market participants that have yet to be manifest in data or statistics. Although this doesn't necessarily lead to adjustments, this appears valued by forecasters, because it reveals what the historic data patterns cannot always expect to reflect.

\footnotetext{
"Econometric models are fine, they describe what has happened in the past, but sometimes there are dynamics in markets which it's useful to find out about in a sort of qualitative way and we will always talk through with people on the ground as to actually what is happening in their markets and that would add information to help and inform the forecasts."

(Forecaster working for Property Consultant)
}

A third potential form of feedback is direct challenge to the forecast numbers, by the suggestion of alternatives. This doesn't generally appear to happen, unless it is accompanied by an argument based on factual accuracy or sentiment issues.

Capturing the first two forms of this feedback is usually done by the forecaster presenting the "draft" forecast to the market team. Usually this is face-to-face, although in some instances it is done by telephone, where the travel logistics (e.g. around European cities) make this more practical. The discovery of factual errors revealed by market feedback generally results in modification of the forecasts; although the scope for this kind of adjustment appears greater the more localised the 
forecasts are, because local market knowledge is likely to have a commensurately

larger impact on the forecast assumptions.

"We'd get feedback, such as oh no, they're not building that 20,000 square metre tower any more, or that guy who was going to relocate here is not coming anymore, or rents weren't that high in 1998, your historical data is wrong. So we'd feed all this in and think about how best to incorporate it. If it's hard factual information, we'd just run the models again and we get a different answer."

(Forecaster working for Property Consultant)

"With the draft forecasts we will then talk to our people on the ground and see whether there any short terms plans that we are missing, are there any specific deals that are happening in the market which we ought to be aware of, are there any other issues that they think the forecasts aren't picking up".

(Forecaster working for Property Consultant)

Where the feedback is based on signals of sentiment or market mood, the response varies more widely. This form of feedback may result in changes, or may simply be set alongside the original numbers as commentary. The discretion on this appears to lie with the forecaster. In large part, the decision between change and just simply comment rests on the extent to which the forecasters are persuaded of the validity of the markets people's views. Merely adding the views as commentary to the forecast appears to be the line of least resistance, although this is tempered by forecasters' recognition of the need to maintain good working relationships with the providers of feedback; relationships which may be prejudiced if the forecasters appear too rigid in their response and fail to take some account of their colleagues' views.

"We'd question their judgement, and whether it was enough to think seriously about modifying the output of the model or, more likely, you would include that in your commentary, to go with the forecast"

(Forecaster working for Property Consultant)

"As far as the client is concerned, we would typically pass on the full reservations or praise, whatever it was that the agents said, even if it wasn't built into the model....so we will say here is our forecast, but you should be aware that there are some more positive views of the market locally or negative views of the market locally."

(Forecaster working for Property Consultant)

"The qualitative information will colour the forecasts in some way. It depends how solid we think the information is. So if we are not particularly happy that the message that they're delivering to us is supported by the information in the data, we won't modify the forecast very much." (Forecaster working for Property Consultant)

Some interviewees drew the distinction between adjustments for the short-term and longer-term forecasts, suggesting that it is only the short-term forecasts that would be 
changed as a result of feedback from those close to the market ${ }^{9}$. Forecasters' willingness to do this is strengthened, however, when the short-term forecast is problematic, as was generally acknowledged to be the case with yield forecasts.

"We will take views from our economist, as to where he thinks the market is going to go, and will then adjust the forecasts for the whole five year period, but the front end will be done by talking to the markets guys".

(Forecaster working for Fund Manager

"'The short-term picture, the agents know, but l'm not going to let the agent tell me what the medium term view might be."

(Forecaster working for Property Consultant)

"For yields, on the one-year view, you'll get a much better view from somebody in the market than you can from someone trying a statistical forecast."

(Forecaster working for Fund Manager)

\subsection{User influences and adjustments}

As well as seeking feedback from colleagues within their own organization whose interest in the forecast is tangential, most forecasters also periodically discuss their current forecasts with internal and external users (clients). Not surprisingly, this is more likely to occur where the forecaster-user relationship is strong, or even formalised, as for example, where the users are part of the same overall organisation or the client relationship is of long-standing. Sometimes forecasters referred to these meetings as being an opportunity to persuade users of the robustness of their forecasts, or even correct users' misconceptions concerning data. Mirroring the feedback from in-house colleagues, however, some interviewees also conceded that the opposite might apply, with information valuable to the forecaster being revealed, as for example, where the market was undergoing fundamental change and the forecasting model becoming less valid.

Most who discussed this issue appeared to value the role of users in helping forecasters to better understand the workings of the market. Most were willing to accept that that their models might not be capturing everything and accordingly were prepared to show some flexibility in adjusting their forecasts to take account of users' insights.

"I think it is very easy as an econometrician to pooh-pooh gut feeling, but actually gut feeling really means that they have their own models which

\footnotetext{
${ }^{9}$ The same appeared true of feedback from users: "Generally, the people in the market, the deal-doers, will always have a slightly different view to the forecasters in the longer term. The shorter term has already been adjusted to their kind of view anyway, in terms of where we think the market currently is." (Forecaster working for Fund Manager)
} 
they have built up over 30 years of experience and they can't articulate them very well but they probably have some validity."

(Forecaster working for Bank)

"This last session convinced me that econometrics won't do the job as we singularly failed to foresee the latest down-turn, whereas our (users) actually did see it, ahead of time. So it's somehow also trying to blend in a sort of high level insight that you can get from these people."

(Forecaster working for Property Company)

A minority took a different view, being more inclined to stand by their models and generally resistant to much more than minor modification to their outputs.

"Why bother with a model if you're then going to change the outputs" (Forecaster working for Property Consultant)

In one instance, with a forecaster whose role in the organization was wider than just forecasting, a different rationale for adjusting the bare forecast was advanced.

\begin{abstract}
"I want to focus on ensuring that our acquisition professionals are focused on the right markets where I think the best performance is going to come from. And if that means altering the rental growth numbers so that they believe them, while keeping those broad calls in place, then I will do that." (Forecaster working for Forecaster/Investment Adviser)
\end{abstract}

There was no evidence of users, including external clients, pressuring forecasters to modify their forecasts. In some instances, however, forecasters appeared to be anticipating client reaction and sometimes pre-adjusting their forecasts or advice to deal with this. This was generally linked to the issue of "extreme" forecasts (infra).

"Our models were certainly saying that there was the threat of declines in rental values in that market in 2000. Now I couldn't go out in a publication and put declining rental values, because nobody would believe me. So you have to present it in a way that makes it acceptable, there has to be an element of acceptability when you present a forecast."

(Forecaster working for Forecaster/Investment Adviser)

\title{
5.3 Adjustments from extreme values
}

There was some evidence from the interviews that forecasters were averse to releasing predictions of significant shifts, such as growth or return in double digits (even though examination of the historical data clearly shows that this happens, sometimes recurrently- e.g. all-property total returns in the late 1970s). The psychological barrier may also involve the transition from positive to negative, rather than just be a question of size. ${ }^{10}$ To some extent, this form of cognitive dissonance appeared to stem from individual's prior experience, or from tacit understandings

10 "They might only be minus two but to me there's a massive great red mark next to it" (Forecaster working for Fund Manager) 
within the organization (the latter based on the relative worth of precise numbers against broad indicators of market direction).

"I suppose you learn, and you're constrained by your own experience in that sense. I mean, if you see anything in double figures, you think, oh my god"

(Forecaster working for Fund Manager)

"Who the hell is going to put down forecasts of minus 20 , or minus 10 , it never happens. Forecasters tend to be conservative in their approach. I think they tend to limit the range of their forecasts. It's very rare to see big numbers, whether positive or negative."

(Forecaster working for Fund Manager)

"There are barriers to the size of forecasts, below 10 and you don't need to go anymore extreme. More importance is attached to getting the relative performance correct." (Forecaster working for Property Consultant)

Two interviewees, however, acknowledged that experienced had taught that extreme forecasts could turn out to be correct (the Spanish office market in the late 1990s being given as one example). In another,

"I can remember when our rental growth figures were coming out for offices in double digits, and we thought "double digits, you've go to be joking!" Unfortunately, they did hit double digits, so it's dangerous to overwrite your model."

(Forecaster working for Fund Manager)

The aversion does not necessarily appear confined to the forecasters, but may also be present in the behaviour of others who might, within the forecast production process, cause adjustments to be made.

"I once came up with a forecast for the industrial market. The figure seemed high, something like minus $27 \%$, rental growth. Anyway it was shaved down because, it's the real world. First of all, the research group shaved it down, to, $18 \%$ or something, because, well, we've never seen one of them before. Then it was shaved down again when it went through to the fund managers - that looks ridiculous, so I think it's got to be minus 12. Anyway, everybody had something to say because they felt uncomfortable with the number, basically, and a big number like that makes you feel uncomfortable."

(Forecaster working for Property Consultant)

The reasons for this aversion appear complex. At one level it is tied to the doubt among forecasters that extreme output values are fundamentally credible, on the basis that their models have limited scope to generate extreme predictions.

"A lot of modellers will tell you, if they're honest, that in modelling rental growth they get very little variability in those rental forecasts, because if you look at a lot of these models, the output is fairly static. To get very wild swings in those numbers, you need very strange things happening to economic variables, which just does not happen. So there is a problem with a lot of models because that volatility isn't there."

(Forecaster working for Forecaster) 
Where such predictions do occur, however, forecasters would scrutinise the forecast assumptions for supportive economic explanations, for co-occurring events that could help explain something that was a valid indicator rather than just a statistical aberration.

"If we see large numbers we probably won't believe them. If the model's generating double digit growth or double digit negative growth then you should really pay attention and say to yourself "well, why don't we believe it or why has the model done that" and then look at it, and say, right, the model's done that because supply is very much under control, or whatever. And really start investigating the series."

(Forecaster working for Fund Manger)

Forecasters appear more likely to expend effort on such investigation if the forecast is being "applied", as for example for valuation purposes or for stock selection, than if it is simply providing background on trends for some wider purpose, such as overall strategy (in which case it would be regarded as an aberration and simply excised).

As noted above, some attributed the aversion to assumptions about user reaction to such figures, and especially to the resulting credibility of those producing figures, with one interviewee suggesting that the property market data underlying the forecast are never sufficiently robust to take a chance in this respect. The fear of getting it wrong - and the consequences to credibility - appeared to be one justification for adopting a conservative stance.

"Big numbers are not necessarily a problem for me but certainly are for my clients. You have to present something that you think that your client base is going to accept, because if you don't present it in that way, they just don't pay regard to it."

(Forecaster working for Forecaster/Investment Adviser)

"What we tend to do is, the range tends to be squeezed a bit to make it look, not so much more appealing but, it's because then you can be maybe less wrong."

(Forecaster working for Fund Manager)

\begin{abstract}
"Very few forecasters that are prepared to put their head above the parapet and say no, we actually think it's $20 \%$ this year, or it's minus $20 \%$. Their name rides on the back of it, and if they get it horribly wrong and they call $20 \%$, and it's actually minus $20 \%$, then it will discredit their forecast and they don't do that, what they do is say it's going to be $10 \%$. That's the way the forecasts are done, they're not calling extremes, no forecaster will." (Forecaster working for Fund Manager)
\end{abstract}

This loss of credibility issue was not wholly confined to the reaction of external clients, with one interviewee referring specifically to in-house organizational tensions as a contributory factor to the forecasters' cautious approach: 
"It had to be flattened off at zero or something like that, just because of the message that might be taken up. In that instance there was political rumbling within companies, with the relationship between research and the agents not particularly good at that time."

(Forecaster working for Property Consultant)

In contrast, some of the interviewees - although a minority - appeared more relaxed about forecasting extreme values, citing markets (e.g. City of London offices) where such patterns were not atypical, or stressing the subsidiary role of forecasting within broader investment advice and the need to meet clients' expectations that advisers will take a strong view - "it's appalling if you say everything is going to be average, it can't add value" (Forecaster working for Bank). However, in a different institutional context, exceeding the average appeared to be more problematic.

"With the local forecasts, it was hard to get anything above average. If you had a very strong result they'd want to temper it down to the average, but the ones below the average weren't tempered up." I have no problem with extreme forecasts but other people don't like it."

(Forecaster working for Fund Manger)

\subsection{The impact of qualitative adjustments}

Although there was a wide difference of opinion on the extent to which the forecast from the quantitative model would change before release of the final figure - and the reasons for doing this - it appears that with most, though not all, forecasters' adjustments are always made. An important factor in determining this appears to be the nature of the markets, with market size and market maturity tending to make the quantitative forecast more resistant to qualitative modifications.

"For some of our European forecasts where our data is less comprehensive, slightly lower quality and the model is not quite so robust, we will take account of what the people on the ground are saying a little bit more."

(Forecaster working for Property Consultant)

The importance of making these adjustments becomes greater at turning points in the market, which the qualitative inputs may capture much better than the statistical data driving the models. Not surprisingly, reaching agreement between the forecasters and the market informants as to when the turning point was approaching or had arrived was "incredibly difficult".

Only three of the interviewees expressed views on the impact of typical adjustments, in terms of the relative contributions of the quantitative and qualitative dimensions of the process. These varied, but in each case the contribution of the qualitative 
adjustment appeared substantial. One interviewee, working for a fund manager, put the qualitative contribution at $50 \%$, possibly less on occasions. He contrasted this with his experience working for a property consultant, where the quantitative contribution was "much more significant". A second, working for an investment adviser, put the qualitative contribution at $30 \%$, which he contrasted with the impression given by the academic forecasting literature, from which "you would get perception that the quants are more important than they actually are". The third, working for a property company - and using a broader range of techniques than most of the interviewees - felt that "econometric modelling is only about $20 \%$ of the process."

\subsection{Herd Behaviour?}

Most of the forecasters who were interviewed were interested in what other forecasters were predicting. A minority were not, other than perhaps to enable them to tell clients their stance in relation to others forecasters. For those who were interested, the availability of others' forecasts, and the quality of what they could see, naturally varied. Sometimes availability only came with a lag, with suppliers unwilling to widely release detailed versions of their forecasts until some time had elapsed.

Availability depended not least on the resources or influence of the "receiving" organization, with some faring better than others.

"In addition to our two our two main providers, we also get forecasts from the likes of Jones Lang, Richard Ellis, DTZ, Healy and Baker, Hillier Parker, King Sturge, and we take it all on board"

(Forecaster working for Fund Manager)

"I get reports from a variety of people. But it's sometimes difficult to get hold of what other people say or what other people think. Some will provide you with the numbers, for a quid pro quo, but other organisations are very secretive and want to keep their numbers to themselves." (Forecaster working for Fund Manager)

Frequently, interest in other people's forecasts was justified as effectively helping to improve the forecaster's understanding of their own forecasts. It appeared to be helpful to know the views of the property market consensus, of the agents and of specialist forecasting houses, on the basis that it was possible via these to seek an understanding of why they held their views. Achieving this understanding is not always possible and it was not wholly clear just how well other forecasts could be interpreted, given that there is a degree of secrecy about the underlying models. This interpretation of reasons for differences and similarities appears to be based at 
the level of broad views or arguments rather than through detailed scrutiny of the models themselves.

"You work out why you are out of line, and if you think your reasons for being out of line are good ones then you remain out of line. But it's difficult to do that unless you can get access to the models that they are using and they are often quite secretive about how exactly they generate the numbers."

(Forecaster working for Bank)

"Without knowing the insides of their models we're not able in detail to judge the reasons why other forecasts may differ. You can make inferences, that they must be making different assumptions about this and that"

(Forecaster working for Property Consultant)

"It's hard to actually investigate and understand why those forecasts are different, because we only anecdotally get information on the other forecasts. So we don't get a lot of detail."

(Forecaster working for Forecaster/Investment Adviser)

Where close analysis of others' forecasts was not feasible, inspecting these forecasts still held attractions, but more to give a fuller picture of what others were doing. For example, a forecast incorporating a radical view might draw attention to an insight previously overlooked. But beyond perhaps broad improvement of forecasters' own insights, it is difficult to discern quite what the consequences of awareness of other forecasts are. According to the interviewees, they appear rarely, if ever, to result in direct changes to forecasts. Some interviewees, however, implied that there may be an underlying herd affect, or at least that the wish not to be too extreme may be a shared one. ${ }^{11}$

"The major private practice firms that produce forecasts tend to be very similar in their approach. I can almost guarantee most of the forecasts... will be kind of clustered because, from experience, people who do forecasts tend to look at other people's forecasts."

(Forecaster working for Fund Manager)

"If you are right people say, well done, and they forget about it, but if you are wrong, people may never forget. So there is this incentive to sort of huddle together"

(Forecaster working for Bank).

Others gave reasons why such similarities might not be surprising.

"The major private practice firms are all using the same kind of systems as producers, the software is generally the same, they tend to do the forecasts the same way, and they will use similar sources of inputs for the economics."

(Forecaster working for Property Consultant)

11 By contrast, this was not the experience of an interviewee with experience of the US, who found it "fascinating how at the same point in time two forecasting houses can have very different views of the world." 
"Other people's forecasts are similar to ours, and I suppose that is because we all look at the same data and we all have the same basic understanding of how markets work. You can see how a group of people who have a basic understanding of economics and real estate markets and a basic understanding of how to build models are probably going to come up with similar sort of forecasts."

(Forecaster working for Bank).

\section{Conclusions}

The demand for forecasts from investors demonstrates their central role in decisions about real estate investment. Uncertainty, however, is inherent in the forecasting process, due to (a) the intrinsic nature of the estimate (as a point drawn from a probability distribution); (b) the problems of data availability and reliability in real estate markets; and (c) the inherent limitations of econometric methods. This uncertainty creates the opportunity and the justifiable motive for forecast modification by both users and producers. The wider literature on forecasting confirms that these issues are not confined to real estate forecasting.

Some of the findings from this investigation are not surprising. Although forecasters are using some common tools (most notably a five year forecasting horizon and a multiple regression approach), and there are embryonic attempts to agree common definitions, real estate forecasters are using a range of inputs and data sets to form models to predict an array of variables for a range of locations. Given the range of choices to be made about the identification and measurement of these variables, at the model formation stage the use of judgement is inevitable.

The findings clearly point to widespread respect from forecasters for input from expert market participants, whose contribution to the process is valued beyond that of market scanning for missing or erroneous data. Resulting adjustments appear well-considered. At the same, and because of the nature of forecasts as frequently part of a wider advice package, forecasters are acutely aware of the importance of maintaining client confidence and credibility. Forecasts need to be acceptable to their users (and purchasers) and consequently forecasters generally have incentives to avoid presenting contentious or conspicuous forecasts. There is clear evidence of these tendencies among a number of the forecasters in this study, with forecasts being adjusted to reduce this kind of risk.

There is little compelling evidence of herd behaviour, other than that manifest via the aversion to extreme forecasts, which appears embedded in the forecast process, if 
not always necessarily in the forecasters as individuals. Where extreme forecasts are generated by a model, forecasters often engage in 'self-censorship' or are 'censored' following in-house consultation. This distrust of large numbers may be a rational bias given the range of uncertainties about the inputs and the models - in addition to the reputational risks referred to above. In this respect, however, it is not surprising that research has found that forecasts are often smooth relative to the underlying market.

As predicated at the outset of this study, it is clear that the forecasting process is more complex than merely carrying out econometric modelling and that the impact of the influences within this process vary considerably across different organizational contexts. This paper has presented only a partial discussion of the full results of the research and further papers will address how forecasts are communicated to users (with particular emphasis on the communication of uncertainty and the limitations of forecasts) and how forecasters' evaluate their success or failure. 


\section{References}

Armstrong S.J. Long-Range Forecasting: From Crystal Ball to Computer, $19852^{\text {nd }}$ Edition, New York: Wiley-Interscience.

Batchelor, R. and Dua, P. Forecasting ideology, forecasting technique and the accuracy of forecasts, International Journal of Forecasting, 1991, 6, 3-10.

Benjamin, J., D. Jud and A. Okaruwa, Forecasting the Stock of Retail Space Using the Koyck Distributed Lag Model, Journal of Property Research, 1993, 10, 3, 185-192.

Brooks, C. and S. Tsolacos, Forecasting Real Estate Returns Using Financial Spreads, Journal of Property Research, 2001, 18, 3, 235-248.

Chaplin, R., An Ex-Post Comparative Evaluation of Office Rent Prediction Models, Journal of Property Valuation and Investment, 1998, 16, 1, 21-37.

Chaplin, R. The Predictability of Real Office Rents, Journal of Property Research, 1999, 16, 1, 21-49.

Chaplin, R., Predicting Real Estate Rents: Walking Backwards into the Future. Journal of Property Investment and Finance, 2000, 18, 3, 352-370.

Clements, M. Rationality and the role of judgment in macroeconomic forecasting, The Economic Journal, 1995, 105, 410-420.

Clements M and Hendry, D. Forecasting non-stationary economic time series, 1999, MIT Press.

Corder, K. Managing Uncertainty, The Bias and Efficiency of Federal Macro-economic Forecasts, 2003, Paper presented at the National Public Management Conference.

Croushore, D. Introducing The Survey of Professional Forecasters, Federal Reserve Bank of Philadelphia Business Review, 1993, November/December, 3-13.

Dalrymple, D.J. Sales forecasting practices, International Journal of Forecasting, 1987, 3, 379-391.

D'Arcy, E., T. McGough and S. Tsolacos, An Econometric Analysis and Forecasts of the Office Rental Cycle in the Dublin Area, Journal of Property Research, 1999, 16, 4, 309-324.

Fildes, R. and H. Stekler, The State of Macroeconomic Forecasting, Journal of Macroeconomics, 2002, 24, 435-468.

Fisher, K. and Statman, M. Cognitive biases in market forecasts: The frailty of forecasts, Institutional Investor, 2002, Fall, 72-81.

Gjaltema, A. Judgement in (Population) Forecasting, Paper presented at European Population Conference, 2001.

Gardiner, C. and J. Henneberry, The Development of a Simple Regional Office Rent Prediction Model, Journal of Valuation, 1988, 7, 1, 36-52.

Gardiner, C. and J. Hennesberry, Predicting Regional Office Rents Using Habit-Persistence Theories, Journal of Property Valuation and Investment, 1991, 9, 3, 215-226.

Griffiths, J. and Wellman, B. Forecasting Bed Needs and Recommending Facilities Plans for Community Hospitals: a review of past performance, Medical Care, 1979, 17, 293-303 
Guilkey, D., How Good are MSA Forecasts? A Review of Major Supply- and Demand-Side Information Providers, Real Estate Finance, 1999, 15, 4, 27-41.

Laster, D., P. Bennett and I.S. Geoum. Rational Bias in Macroeconomic Forecasts, The Quarterly Journal of Economics, 1999, 114, 293-318

Malizia, E., Forecasting Demand for Commercial Real Estate Based on the Economic Fundamentals of US Metro Markets, Journal of Real Estate Research, 1991, 6, 251-265.

McClure, K., Estimating Occupied Office Space: Comparing Alternative Forecast Methodologies, Journal of Real Estate Research, 1991, 6, 3, 305-314.

McGough, T. and S. Tsolacos, Forecasting Commercial Rental Values Using ARIMA Models, Journal of Property Research, 1995, 13, 6-22.

Miles, M. and A. Huberman, Qualitative Data Analysis: An Expanded Sourcebook, 1994, London, Sage Publications.

Mitchell, P. and P. McNamara, Issues in the Development and Application of Property Market Forecasting: the Investor's Perspective, Journal of Property Finance, 1997, 8, 4, 363-376.

Newell, G. McAllister, P. and Brown, S. The accuracy of real estate forecasting, Paper presented at 2003 ERES conference, Helsinki.

Nordhaus, W. Forecasting efficiency: concepts and applications, Review of Economics and Statistics, 1987, 69, 667-74.

O'Connor, M., Remus, W. and Griggs, K. Going Up-Going Down: How Good Are People at Forecasting Trends and Changes in Trends?, Journal of Forecasting, 1997, 16, 3, 165-176.

Sivitanides, P., Predicting Office Returns: 1997-2001, Real Estate Finance (Spring), 1998, 33-42.

Thomaidis, N. The Implications of Behavioural Finance for the Modelling of Securities Prices, downloaded from http://www.quantnotes.com/fundamentals/behaviouralfinance/paperquantnotes.pdf.

Tsolacos, S., Econometric Modelling and Forecasting of New Retail Developments. Journal of Property Research, 1998, 15, 4, 265-283.

Tsolacos, S., J. Keogh and T. McGough, Modelling Use, Investment and Development in the British Office Market, Environment and Planning A, 1998, 30, 8, 1409-1427.

Turner, D.S. The role of judgement in macro-economic forecasting, Journal of Forecasting, 1990, 9, 315-345.

Tversky, A. and Kahneman, D. Judgement under uncertainty: heuristics and biases. Science, 1974, 185, 1124 - 1131.

Walonick, D. An Overview of Forecasting Methodology downloaded from http://wwwstatpac.com/research-papers/forecasting.htm

Welch, E., Bretschneider, S. and Rohrbaugh, J, Accuracy of judgemental extrapolation of time series data, International Journal of Forecasting, 1998, 14, 95-110.

Wheaton, W. and R. Torto, Vacancy Rates and the Future of Office Rents, AREUEA Journal, $1988,16,430-436$.

Wilson, P. and J. Okunev, Enhancing Information Use To Improve Predictive Performance In Property Markets, Journal of Property Investment and Finance, 2001, 19, 6, 472-497. 
Wilson, P., J. Okunev, C. Ellis and D. Higgins, Comparing Univariate Forecasting Techniques in Property Markets, Journal of Real Estate Portfolio Management, 2000, 6, 3, 283-306. 
Appendix 1

\begin{tabular}{|c|c|c|}
\hline Code Name & Description of what code refers to & $\begin{array}{l}\text { Code } \\
\text { No. }\end{array}$ \\
\hline Big numbers & $\begin{array}{l}\text { The nature of the forecaster's reaction to forecast outputs } \\
\text { which are extreme in relation to the "normally" expected range }\end{array}$ & $\mathbf{1}$ \\
\hline $\begin{array}{l}\text { Communicating with } \\
\text { clients }\end{array}$ & $\begin{array}{l}\text { Discussion of the forecast with clients (excluding discussion in } \\
\text { its production), including identification of the quantitative and } \\
\text { qualitative components and their robustness. }\end{array}$ & 2 \\
\hline Cycles & Discussion of aspects of the cyclical nature of markets & 3 \\
\hline Data consids & $\begin{array}{l}\text { A general code for data considerations not covered by the more } \\
\text { specific data consideration codes. }\end{array}$ & 4 \\
\hline $\begin{array}{l}\text { Data consids - } \\
\text { availaibility variatn }\end{array}$ & $\begin{array}{l}\text { The variations in the availability and/or qualityof data across } \\
\text { different markets and sectors. }\end{array}$ & 5 \\
\hline $\begin{array}{l}\text { Data consids - base to } \\
\text { fcast off }\end{array}$ & $\begin{array}{l}\text { The problem of correctly identifying the current level of rent (or } \\
\text { yield) off which to base future forecasts. }\end{array}$ & 6 \\
\hline $\begin{array}{l}\text { Data consids - data } \\
\text { measurement }\end{array}$ & $\begin{array}{l}\text { The problem of consistency in the way data is measured, } \\
\text { expressed and recorded (for example, differing definition and } \\
\text { interpretations of prime, CBD etc). }\end{array}$ & 7 \\
\hline Ease-difficulty & $\begin{array}{l}\text { The relative ease or difficulty of property market forecasting in } \\
\text { comparison to forecasting other economic variables (excluding } \\
\text { the particular problems of yield forecasting). }\end{array}$ & 8 \\
\hline $\begin{array}{l}\text { Ease-difficulty - Yield } \\
\text { forecasts }\end{array}$ & $\begin{array}{l}\text { The particular problem of yield forecasting and reasons } \\
\text { attached to this. }\end{array}$ & 9 \\
\hline Ec'metric models & $\begin{array}{l}\text { The general issue of the use of econometric models as a model } \\
\text { form in property forecasting, including their nature and } \\
\text { attributes. }\end{array}$ & 10 \\
\hline $\begin{array}{l}\text { Ec'metric models -Re- } \\
\text { est or restruct }\end{array}$ & $\begin{array}{l}\text { The particular issue of how often and for what reason(s) } \\
\text { econometric models used in property forecasting are re- } \\
\text { estimated, recalibrated or more radically restructured. }\end{array}$ & 11 \\
\hline Fcast context & $\begin{array}{l}\text { A general code for contextual forecasting issues not captured } \\
\text { by any of the specific contextual codes. }\end{array}$ & 12 \\
\hline $\begin{array}{l}\text { Fcast context - others } \\
\text { role in Produ }\end{array}$ & The role of non-forecasters in the production of forecasts. & 13 \\
\hline $\begin{array}{l}\text { Fcast context - what } \\
\text { form of models }\end{array}$ & $\begin{array}{l}\text { A description of the form of model(s) used in property } \\
\text { forecasting. }\end{array}$ & 14 \\
\hline $\begin{array}{l}\text { Fcast context - what } \\
\text { markets\&sectors }\end{array}$ & $\begin{array}{l}\text { A description of the markets and/or sectors covered by the } \\
\text { forecaster's forecasts. }\end{array}$ & 15 \\
\hline $\begin{array}{l}\text { Fcast context - what } \\
\text { vars forecast }\end{array}$ & $\begin{array}{l}\text { A description of the output variables produced and/or published } \\
\text { from the forecaster's forecasts. }\end{array}$ & 16 \\
\hline $\begin{array}{l}\text { Fcast context - who are } \\
\text { the clients }\end{array}$ & A description of the external or in-house users of the forecasts. & 17 \\
\hline $\begin{array}{l}\text { Fcast context- F's non-F } \\
\text { role }\end{array}$ & $\begin{array}{l}\text { Discussion of any aspects of the forecasters role that extends } \\
\text { beyond pure forecast production. }\end{array}$ & 18 \\
\hline $\begin{array}{l}\text { Fcast context- why } R \\
\text { fcasts produced }\end{array}$ & $\begin{array}{l}\text { The reasons why forecasts are produced and/or the purposes to } \\
\text { which they are applied. }\end{array}$ & 19 \\
\hline Fcast failures & $\begin{array}{l}\text { Descriptions of circumstances when forecasts have been } \\
\text { significantly incorrect, and possible discussion of reasons why } \\
\text { (but excluding specific instance of structural breaks and the } \\
\text { London downturn). }\end{array}$ & 20 \\
\hline
\end{tabular}




\begin{tabular}{|c|c|c|}
\hline $\begin{array}{l}\text { Fcast failures - Lond } \\
\text { downturn }\end{array}$ & $\begin{array}{l}\text { Discussion of the specific problem of forecasting the London } \\
\text { downturn of recent times. }\end{array}$ & 21 \\
\hline $\begin{array}{l}\text { Fcast failures - reliance } \\
\text { on MEFs }\end{array}$ & $\begin{array}{l}\text { The specific problem of the reliance of property forecasts on } \\
\text { macro-economic forecasts (NB this links to the node: Mac-econ } \\
\text { fcasts - Nature of vars.) }\end{array}$ & 22 \\
\hline $\begin{array}{l}\text { Fcast failures - } \\
\text { structural breaks }\end{array}$ & $\begin{array}{l}\text { Discussion of structural break as a reason for a model failing or } \\
\text { becoming unsuitable in its existing form. }\end{array}$ & 23 \\
\hline Fcast horizon & The future time horizon(s) over which forecasts are produced. & 24 \\
\hline $\begin{array}{l}\text { Fcast horizon - Mean } \\
\text { reversion }\end{array}$ & The nature of the assumptions about mean reversion. & 25 \\
\hline Freqcy of production & How often the forecasts are produced and/or updated. & 26 \\
\hline From market to building & $\begin{array}{l}\text { Discussion of issues relating to the transfer of forecasts of } \\
\text { markets/market sectors/geographical sectors to specific } \\
\text { buildings. }\end{array}$ & 27 \\
\hline Get fcast right & $\begin{array}{l}\text { A general code for issues relating to getting the forecast right } \\
\text { that are not captured by the more specific codes relating to } \\
\text { this. }\end{array}$ & 28 \\
\hline $\begin{array}{l}\text { Get fcast right- feeling } \\
\text { right }\end{array}$ & $\begin{array}{l}\text { Interviewees' explanations of what makes a forecast "feel" right } \\
\text { or wrong when it is first produced. }\end{array}$ & 29 \\
\hline $\begin{array}{l}\text { Get fcast right- } \\
\text { rules4acceptability }\end{array}$ & $\begin{array}{l}\text { The rules, checks or procedures adopted to evaluate the } \\
\text { robustness (generally statistical) of the model before it is finally } \\
\text { agreed upon and prior to wider dissemination }\end{array}$ & 30 \\
\hline $\begin{array}{l}\text { Herd behaviour \& } \\
\text { others' forecasts }\end{array}$ & $\begin{array}{l}\text { The extent to which forecasters are aware of other people's } \\
\text { forecasts of the same variables, the perceived usefulness of this } \\
\text { knowledge and its impact on forecaster behaviour. }\end{array}$ & 31 \\
\hline How fcasts used & $\begin{array}{l}\text { The forecaster's view as to the general appropriateness of the } \\
\text { use to which the forecasts are put. }\end{array}$ & 32 \\
\hline $\begin{array}{l}\text { How fcasts used - by } \\
\text { clients }\end{array}$ & $\begin{array}{l}\text { Description of the specific uses to which forecasts are put by } \\
\text { clients. }\end{array}$ & 33 \\
\hline $\begin{array}{l}\text { How fcasts used - by } \\
\text { others }\end{array}$ & $\begin{array}{l}\text { Description of the specific uses to which forecasts are put by } \\
\text { users other than clients or valuers. }\end{array}$ & 34 \\
\hline $\begin{array}{l}\text { How fcasts used - by } \\
\text { valuers }\end{array}$ & $\begin{array}{l}\text { Description of the specific uses to which forecasts are put by } \\
\text { valuers. }\end{array}$ & 35 \\
\hline $\begin{array}{l}\text { How fcasts used - } \\
\text { control }\end{array}$ & $\begin{array}{l}\text { The nature of the forecaster's control, or lack of control, over } \\
\text { the use by others of his/her/their forecasts. }\end{array}$ & 36 \\
\hline $\begin{array}{l}\text { Interaction between } \\
\text { models }\end{array}$ & $\begin{array}{l}\text { The linkages between models that cover different markets (e.g. } \\
\text { regional-national, regional-local) and between different types of } \\
\text { model (i.e. times series vs cross sectional). }\end{array}$ & 37 \\
\hline $\begin{array}{l}\text { Mac-econ fcasts - } \\
\text { Nature of vars }\end{array}$ & $\begin{array}{l}\text { Discussion of the nature of the variables used as inputs to } \\
\text { macro-economic forecasts, the problems associated with this } \\
\text { and the implications for the use of macro-economic outputs as } \\
\text { inputs to property forecasts. }\end{array}$ & 38 \\
\hline $\begin{array}{l}\text { ac-econ fcasts-sources } \\
\& \text { usefulness }\end{array}$ & $\begin{array}{l}\text { Sources of macro-economic forecast data and general } \\
\text { discussion of their usefulness (but excluding specific discussion } \\
\text { relating to any adjustments to such data - see code "Q adjusts } \\
\text { to inputs"). }\end{array}$ & 39 \\
\hline $\begin{array}{l}\text { Other behavioural } \\
\text { factors }\end{array}$ & $\begin{array}{l}\text { Catch-all code for behavioural factors and not covered by other } \\
\text { codes. }\end{array}$ & 40 \\
\hline Prop-cf-Econ fcasts & $\begin{array}{l}\text { Discussion of the similarities and/or differences between } \\
\text { forecasting of property variables compared to forecasting of } \\
\text { other economic variables. }\end{array}$ & 41 \\
\hline
\end{tabular}




\begin{tabular}{|c|c|c|}
\hline$Q$ adjusts 2 inputs & $\begin{array}{l}\text { Discussion of whether outputs from macro-economic models } \\
\text { are adjusted before being input to property forecasting models } \\
\text { and reasons for any such adjustments. }\end{array}$ & 42 \\
\hline$Q$ adjusts2outputs & $\begin{array}{l}\text { Discussion of qualitative adjustments to forecasts and not } \\
\text { captured in any of the related more specific codes. }\end{array}$ & 43 \\
\hline $\begin{array}{l}Q \text { adjusts2outputs- } \\
\text { clients aghast }\end{array}$ & $\begin{array}{l}\text { Specific instances of where outputs adjusted prior to publication } \\
\text { because they are perceived as unacceptable to clients and/or } \\
\text { markets. }\end{array}$ & 44 \\
\hline $\begin{array}{l}\text { Q adjusts2outputs- } \\
\text { Inhou consultation }\end{array}$ & $\begin{array}{l}\text { The nature of in-house consultation prior to finalisation or } \\
\text { publication of the property forecast and the nature of any } \\
\text { consequent adjustments to the forecast prior to its adoption. }\end{array}$ & 45 \\
\hline $\begin{array}{l}Q \text { adjusts2outputs-initial } \\
\text { is final }\end{array}$ & $\begin{array}{l}\text { The frequency with which the initial forecast output is adopted } \\
\text { as the final figure and discussion surrounding this (and not } \\
\text { covered by other related codes). }\end{array}$ & 46 \\
\hline $\begin{array}{l}Q \text { adjusts2outputs- } \\
\text { market sentiment }\end{array}$ & $\begin{array}{l}\text { The particular influence of market sentiment upon adjustments } \\
\text { made to initial property forecasts before their finalisation. }\end{array}$ & 47 \\
\hline $\begin{array}{l}\text { Q adjusts2outputs-user } \\
\text { consultation }\end{array}$ & $\begin{array}{l}\text { The role and nature of consultation with users of forecasts as it } \\
\text { relates to adjustments of initial forecasts prior to finalisation } \\
\text { and also to ongoing adjustment of forecasts models over time. }\end{array}$ & 48 \\
\hline QuantQual balance & $\begin{array}{l}\text { Discussion of perceptions of the respective contributions of the } \\
\text { quantitative and qualitative dimensions of the process to the } \\
\text { final figure. }\end{array}$ & 49 \\
\hline Reviewing success & $\begin{array}{l}\text { Discussion of the concept of success in forecasting not captured } \\
\text { by related more specific codes. }\end{array}$ & 50 \\
\hline $\begin{array}{l}\text { Reviewing success - } \\
\text { procedures }\end{array}$ & $\begin{array}{l}\text { Description of any formal procedures used to compare past } \\
\text { forecasts with actual outturn and discussion around this. }\end{array}$ & 51 \\
\hline $\begin{array}{l}\text { Reviewing success - } \\
\text { timing it right }\end{array}$ & $\begin{array}{l}\text { Perceptions of the importance of the timing aspect of "success" } \\
\text { in forecasting. }\end{array}$ & 52 \\
\hline $\begin{array}{l}\text { Reviewing success- } \\
\text { Absol vs Rel }\end{array}$ & $\begin{array}{l}\text { The relative importance of absolute predictive success } \\
\text { compared to success in predicting the relative performance of } \\
\text { assets. }\end{array}$ & 53 \\
\hline Role byond fcasting & $\begin{array}{l}\text { The role or activities of the forecaster additional to the pure } \\
\text { forecast production. }\end{array}$ & 54 \\
\hline $\begin{array}{l}\text { Role byond fcasting- } \\
\text { Sellg the fcast }\end{array}$ & $\begin{array}{l}\text { The presence or not, nature and importance of, selling the } \\
\text { forecast as a necessary part of the forecasting process. }\end{array}$ & 55 \\
\hline The house view & $\begin{array}{l}\text { The concept of the house view and discussion about its role } \\
\text { and importance in forecasting. }\end{array}$ & 56 \\
\hline The story & $\begin{array}{l}\text { The concept of the story and its role and importance in } \\
\text { forecasting. }\end{array}$ & 57 \\
\hline Uncertainty & $\begin{array}{l}\text { A general code for aspects of uncertainty in property forecasts } \\
\text { for issues not captured by the related more specific codes. }\end{array}$ & 58 \\
\hline $\begin{array}{l}\text { Uncertainty - means of } \\
\text { expressing }\end{array}$ & $\begin{array}{l}\text { The methods, if any, adopted to convey the uncertainty } \\
\text { inherent in property forecasts and discussion of problems } \\
\text { related to this. }\end{array}$ & 59 \\
\hline $\begin{array}{l}\text { Uncertainty- } \\
\text { Communicating to } \\
\text { clients }\end{array}$ & $\begin{array}{l}\text { Discussion of the methods adopted, if any, to convey to clients } \\
\text { the uncertainty inherent in property forecasts, and discussion of } \\
\text { the problems surrounding this (including the risks to forecaster } \\
\text { credibility of raising this issue with clients). }\end{array}$ & 60 \\
\hline Unexpected shocks & $\begin{array}{l}\text { How forecasts are modified following significant and } \\
\text { unexpected events. }\end{array}$ & 61 \\
\hline
\end{tabular}

